\title{
Pranlukast, a novel leukotriene receptor antagonist: results of the first European, placebo controlled, multicentre clinical study in asthma
}

\author{
N C Barnes, J-C Pujet on behalf of an International Study Group
}

The London Chest Hospital, Department of Respiratory Medicine, Bonner Road, London E2 9JX, UK

N C Barnes

Du Centre de Diagnostic et de Readaptation CardioRespiratoire, 74 Rue de la Colonie, 75013 Paris, France

J-C Pujet

This study was presented in part at the American

Thoracic Society Meeting

Seartle, Washington, USA in

May 1995.

Correspondence to:

Dr N C Barnes.

Received 21 November 1995

Returned to authors

9 February 1996

Revised version received

27 February 1997

Accepted for publication

28 February 1997

\section{Abstract}

Background - Leukotriene receptor antagonists have been shown to protect against bronchoconstriction induced by antigens, exercise, and cold air. There are relatively few clinical studies reported in patients with asthma. The present study is the first clinical evaluation of pranlukast (SB 205312, ONO-1078) outside Japan in patients with asthma.

Methods - A randomised, double blind, placebo controlled, parallel group, multicentre four week study of the safety and tolerability of oral pranlukast, 225 or $337.5 \mathrm{mg}$ twice daily, was performed in patients with mild to moderate asthma. Preliminary efficacy data were obtained; the main efficacy variables evaluated were forced expiratory volume in one second $\left(F E V_{1}\right)$ and morning domiciliary (home) peak expiratory flow rates (PEFR). Clinic PEFR and daytime and night-time asthma symptom scores were also recorded.

Results - Compared with the placebo group the improvement in morning home PEFR was statistically significant at all time points for patients receiving pranlukast $337.5 \mathrm{mg}$ twice daily and at weeks 1 and 2 for those treated with pranlukast in a dose of $225 \mathrm{mg}$ twice daily. Mean morning home PEFR increased by 10.8 to $18.61 /$ $\min (95 \%$ CI 0.2 to $29.31 / \mathrm{min})$ in patients treated with pranlukast compared with a slight deterioration in those given placebo. FEV $_{1}$ significantly increased within one hour after the first dose of pranlukast compared with baseline and this increase was maintained for eight hours. Improvements in trough $\mathrm{FEV}_{1}$ - that is, at the end of the dosing interval - were statistically significant for the group treated with pranlukast $225 \mathrm{mg}$ twice daily compared with placebo at week 4. Mean increases in FEV ranged from $210 \mathrm{ml}$ to $340 \mathrm{ml}(95 \%$ CI 60 to $500 \mathrm{ml}$ ) at trough in the pranlukast group. Patients treated with pranlukast also showed improvements in summary symptom and night-time asthma scores. Pranlukast was well tolerated, and no drug related changes in haematological and biochemical variables were observed.

Conclusions - Pranlukast, an oral leukotriene receptor antagonist, is well tolerated and is effective for the treatment of asthma. It increased $\mathrm{FEV}_{1}$ within one hour of dosing, improved patient summary symptom and night-time asthma scores, and reduced the use of rescue bronchodilators, thus providing further evidence of a role for leukotrienes in the pathogenesis of asthma.

(Thorax 1997;52:523-527)

Keywords: leukotriene receptor antagonist, asthma, pranlukast, SB 205312, ONO-1078.

Since the structure of leukotrienes was described in $1979,{ }^{1}$ considerable effort has been made to develop drugs that block the leukotriene receptor or inhibit synthesis of leukotrienes. Challenge studies using a number of leukotriene receptor antagonists or 5-lipoxygenase inhibitors have shown that leukotrienes play an important part in the early and late responses to bronchoconstriction induced by inhaled antigen, ${ }^{23}$ exercise, ${ }^{4}$ and cold air. ${ }^{5}$ Comparatively few reports have evaluated leukotriene antagonists or synthesis inhibitors in patients who have chronic asthma. ${ }^{6-8}$

Pranlukast (SB 205312, ONO-1078) is the first leukotriene receptor antagonist on the market and is available in Japan for the treatment of asthma. It has been shown to block bronchoconstriction induced by leukotriene $\mathrm{D}_{4}$ $\left(\mathrm{LTD}_{4}\right)$ and antigen. ${ }^{910}$ The present clinical study was the first European multicentre evaluation of pranlukast, in doses of $225 \mathrm{mg}$ twice daily (the marketed dose in Japan) or $337.5 \mathrm{mg}$ twice daily compared with placebo, in patients with asthma. The doses were chosen to assess whether compensation for greater Caucasian body weight would be necessary. The primary objectives of the study were to evaluate the safety and tolerability of pranlukast and to obtain preliminary evidence of the efficacy of the drug in patients with chronic asthma.

\section{Methods}

PATIENT SELECTION

Men or women aged 18-70 years with an established diagnosis of asthma, a forced expiratory volume in one second $\left(\mathrm{FEV}_{1}\right)$ of 50 $80 \%$ of predicted values, and an improvement of at least $15 \%$ within 30 minutes of taking salbutamol (200-400 $\mu \mathrm{g})$ from a metered dose inhaler were eligible to participate in the study. 
Patients abstained from salbutamol for eight hours prior to this acute bronchodilator test.

Patients were permitted to take inhaled steroids (up to $1000 \mu \mathrm{g} /$ day beclomethasone dipropionate or its equivalent) and on-demand salbutamol during the study. However, they could not take disodium cromoglycate or nedocromil sodium for six weeks or oral steroids for eight weeks before entry to the study. Oral methylxanthines, oral and inhaled long acting $\beta_{2}$ agonists, inhaled anticholinergics, and oral antihistamines had to be withdrawn at least five half lives before the start of the study to ensure no residual effects.

Patients who had poorly controlled asthma, an active smoking history (within six months of entry to the study), recent upper or lower respiratory infections, or other clinically significant or potentially confounding diseases were excluded.

All patients provided written informed consent before participating in the study, and the protocol was approved by the ethics committee at each research centre.

\section{STUDY DESIGN}

The study was of a randomised, double blind, placebo controlled, multicentre, parallel group design with a two week single blind placebo run-in phase, followed by a four week double blind treatment phase, and a 1-2 week runout phase. During the treatment phase patients were randomised to one of three treatment groups: pranlukast $225 \mathrm{mg}(\mathrm{n}=46), 337.5 \mathrm{mg}$ $(\mathrm{n}=45)$, or matching placebo $(\mathrm{n}=44)$ twice daily. Both doses of pranlukast and placebo were administered as identical capsules.

Patients who successfully completed all screening assessments (routine history and examination, haematology, biochemistry, urinalysis, and 12 lead ECG) and satisfied study inclusion and exclusion criteria were given placebo capsules on a single blind basis. They were instructed to take capsules with water 30 minutes before breakfast ( 08.00 hours) and in the evening (20.00 hours) after a meal. In addition, patients were given peak flow meters (mini-Wright, Airmed, Harlow, Essex, UK) and were instructed in their use. Diary cards were used to record symptom severity and use of all medications, including on-demand salbutamol (100 $\mu \mathrm{g} /$ actuation). Patients were scheduled to visit the clinic at the same time of day 14 days after screening, at the end of one, two, and four weeks of double blind treatment, and 1-2 weeks after treatment was stopped.

Following the placebo run-in phase, patients who had complied with the treatment regimen and who had completed their diary cards were randomised to receive double blind treatment. They attended the clinic in the morning, having refrained from taking inhaled steroids and salbutamol for eight hours. Baseline $\mathrm{FEV}_{1}$ and peak expiratory flow rate (PEFR) were measured and patients received the first dose of study medication. FEV 1 and PEFR were measured again $30,60,90$, and 120 minutes after the medication and then hourly for a further six hours. At subsequent visits to the clinic patients were asked not to take their morning drug dose until after the spirometry and PEFR had been measured. They only had measurements made for eight hours on the first day of drug dosing.

The primary efficacy variables were the trough $\mathrm{FEV}_{1}$ measured in the morning in the clinic, and morning domiciliary PEFR. Pulmonary function was assessed in the clinic by measuring $\mathrm{FEV}_{1}$, forced vital capacity, and PEFR three times before the administration of study medication (the highest reading of each was used for statistical analysis). Patients also measured their PEFR at home twice a day with the peak flow meter, before the morning dose and after the evening dose of study medication; each time three values were recorded and the highest value was used on the diary card. Each inhalation of salbutamol and inhaled corticosteroids was also recorded on the diary card, as well as daytime and night-time asthma symptom severity which was rated on a five point scale: $0=$ none (no symptoms), $1=$ mild, $2=$ moderate, $3=$ severe, and $4=$ very severe symptoms. The daytime and night-time asthma symptom scores were combined into an overall summary symptom score.

Safety was assessed at each visit based on the incidence of adverse experiences, vital signs, laboratory evaluations, ECG tracings, and physical and respiratory examinations. Patients who withdrew from the study because of adverse experiences were followed to determine the final outcome of these events.

\section{STATISTICAL ANALYSES}

All analyses of efficacy were performed using data from all patients who received at least one dose of randomised treatment. Analysis of variance (ANOVA) was used to assess differences between treatment groups for normally distributed, continuous variables. Within treatment comparisons were made using paired $t$ tests. Because the primary objective of the study was to assess the safety and tolerability of pranlukast, no formal sample size calculations were performed. The goal was to have at least 120 patients enrolled to yield at least 90 evaluable patients (30 in each treatment group). For efficacy analyses, statistical tests were performed at a significance level of 5\% ( $\alpha=0.05$, two tailed test).

The primary between treatment comparisons were the analyses of trough $\mathrm{FEV}_{1}$ (the clinic measurement before daily dosage) and morning home PEFR measurements. ANOVA was used to analyse the change from trough baseline values of $\mathrm{FEV}_{1}$ at each time point following the first dose and the change from baseline (highest value at week 0 ) for trough values on a visit-wise and end point - that is, the last available post-baseline measurement - basis. Paired $t$ tests were used to compare the morning and evening home PEFR measurements with the respective run-in values for each inter-visit period, and ANOVA was used for comparisons between treatment groups. Patients who took inhaled salbutamol during the eight hours preceding the visits at weeks 1,2 , and 4 were 
Table 1 Baseline patient demographics*

\begin{tabular}{lccc}
\hline Demographic parameter & $\begin{array}{l}\text { Placebo group } \\
(n=44)\end{array}$ & $\begin{array}{l}\text { Pranlukast } \\
225 \text { mg group } \\
(n=46)\end{array}$ & $\begin{array}{l}\text { Pranlukast } \\
337.5 \text { mg group } \\
(n=45)\end{array}$ \\
\hline Sex & 15 & 19 & 18 \\
$\quad$ Women (n) & 29 & 27 & 27 \\
Men (n) & $38.3(18-67)$ & $38.9(19-70)$ & $33.6(18-69)$ \\
Mean (range) age (years) & 70.5 & 60.9 & 60.0 \\
Concomitant ICS use (\%) & $792(242)$ & $800(309)$ & $829(277)$ \\
$\quad$ Mean (SD) total daily dose at & $400-1500$ & $100-1500$ & $300-1500$ \\
$\quad$ baseline (mg) & $2.44(0.10)$ & $2.46(0.13)$ & $2.40(0.10)$ \\
Range (mg) & $67(1.6)$ & $68(1.8)$ & $66(1.6)$ \\
Mean (SE) FEV 1 (1) & $351(16.0)$ & $342(15.8)$ & $339(14.4)$ \\
Mean (SE) FEV $(\%$ predicted) & & &
\end{tabular}

ICS $=$ inhaled corticosteroids; $\mathrm{FEV}_{1}=$ forced expiratory volume in one second; $\mathrm{PEFR}=$ peak expiratory flow rate.

* Baseline after single blind placebo run in immediately before study medication.

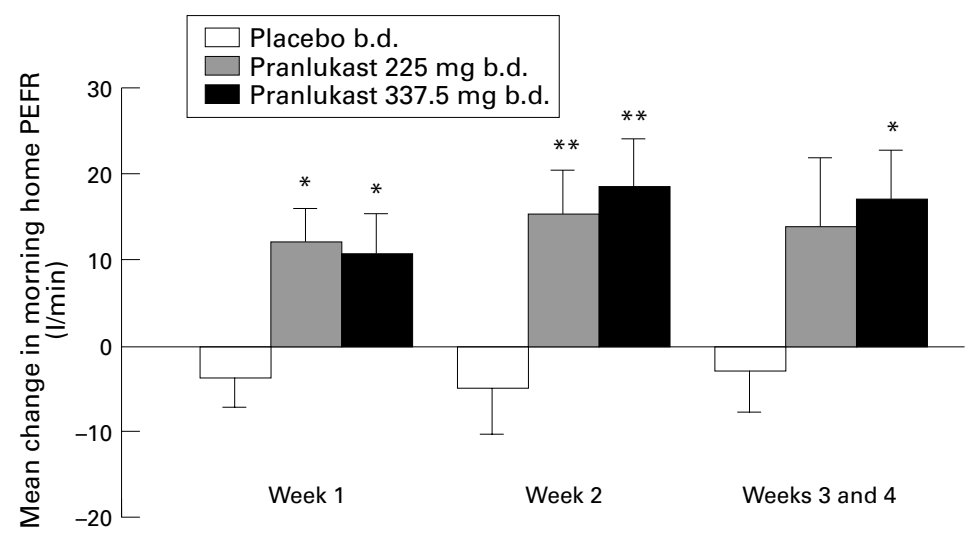

Figure 1 Mean (SE) change in average daily morning home PEFR (l/min) from baseline following one, two, and four weeks of treatment with twice daily doses of pranlukast $225 \mathrm{mg}, 337.5 \mathrm{mg}$, or placebo. ${ }^{*} p<0.05$ compared with placebo; ${ }^{* *} p<0.01$ compared with placebo.

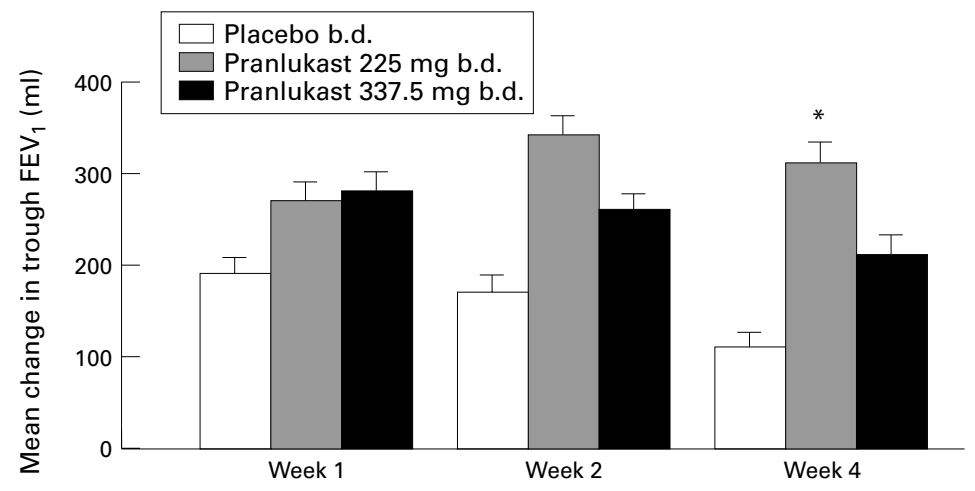

Figure 2 Mean (SE) change in trough $\mathrm{FEV}_{1}$ ( $\mathrm{ml}$ ) from baseline following one, two, and four weeks of treatment with twice daily doses of pranlukast $225 \mathrm{mg}$, 337.5 mg, or placebo. ${ }^{*} p<0.05$ compared with placebo.

excluded from the analyses of pulmonary function test results for the violating visit(s) only.

Daytime and night-time asthma symptom scores were totalled each day to produce a summary symptom score, and an average of these values was determined for each inter-visit period. Paired $t$ tests were used to compare summary symptom scores with scores obtained during the placebo run-in phase for each intervisit period, and ANOVA was used for between treatment group comparisons. The use of salbutamol was analysed in a similar manner.
Adverse experiences were tabulated using the World Health Organisation coding system, and incidence rates were summarised descriptively by treatment group.

\section{Results}

PATIENT CHARACTERISTICS

One hundred thirty five patients were randomised to the three treatment groups; patient demographics are shown in table 1. Of these 135 randomised patients, eight did not complete the study: six patients withdrew because of adverse experiences, one patient was withdrawn for a protocol violation, and one was lost to follow up. Forty two patients in the group treated with pranlukast $225 \mathrm{mg}$ twice daily completed the study, as did 42 in the group receiving pranlukast $337.5 \mathrm{mg}$ twice daily and 43 in the placebo group. Of the six patients who discontinued because of adverse experiences, two in the pranlukast $225 \mathrm{mg}$ group, one in the pranlukast $337.5 \mathrm{mg}$ group, and one in the placebo group withdrew because of an exacerbation of asthma, one in pranlukast $337.5 \mathrm{mg}$ group withdrew because of an injury, and one in the pranlukast $337.5 \mathrm{mg}$ group withdrew because of diarrhoea.

\section{HOME PEFR}

During the four week double blind treatment period the mean increase in morning home PEFR was statistically significant at all time points for the group treated with pranlukast $337.5 \mathrm{mg}$ and at weeks 1 and 2 for the group given $225 \mathrm{mg}$ pranlukast compared with placebo (fig 1). No difference was noted between the pranlukast $225 \mathrm{mg}$ and $337.5 \mathrm{mg}$ treatment groups. The difference in evening home PEFR was not significant.

CLINIC SPIROMETRIC MEASUREMENTS

The improvement in trough $\mathrm{FEV}_{1}$ at week 4 was statistically significant for patients taking pranlukast in a twice daily dose of $225 \mathrm{mg}$ compared with those taking placebo (fig 2). No significant differences in the changes between the groups were seen at other times.

Clinic morning PEFR measurements were significantly improved in both pranlukast treatment groups compared with baseline values, although no significant differences were observed between the active treatment groups and those receiving placebo.

$\mathrm{FEV}_{1}$ significantly increased within one hour after the first dose of pranlukast, 225 or $337.5 \mathrm{mg}$, compared with baseline and this increase was maintained for eight hours. $\mathrm{FEV}_{1}$ was also increased in patients treated with placebo, but this increase was not significant at five, seven, and eight hours (fig 3). No differences were found between the groups. 


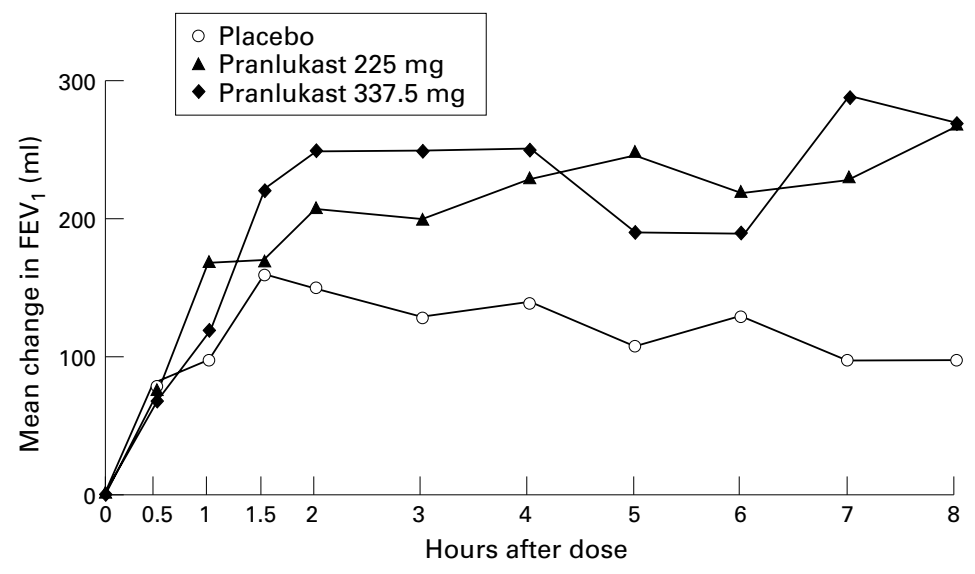

Figure 3 Mean change in FEV $(\mathrm{ml})$ from baseline from 0 to 8 hours following single dose administration of pranlukast $225 \mathrm{mg}, 337.5 \mathrm{mg}$, or placebo. $p<0.05$ compared with baseline values at all time points except pranlukast $337.5 \mathrm{mg}$ at 0.5 hours and placebo at five, seven, and eight hours; $p=N S$ between treatment groups.

Table 2 Symptom scores and salbutamol use (mean change from baseline at end point and confidence intervals)

\begin{tabular}{|c|c|c|c|}
\hline & $\begin{array}{l}\text { Placebo group } \\
(n=44)\end{array}$ & $\begin{array}{l}\text { Pranlukast } \\
225 \text { mg group } \\
(n=46)\end{array}$ & $\begin{array}{l}\text { Pranlukast } \\
337.5 \mathrm{mg} \text { group } \\
(n=45)\end{array}$ \\
\hline \multicolumn{4}{|l|}{ Summary symptom score } \\
\hline Mean baseline value & 1.38 & 1.62 & 1.92 \\
\hline $\begin{array}{l}\text { Mean }(95 \% \mathrm{CI}) \text { change } \\
\text { from baseline }\end{array}$ & $\begin{array}{l}0.01 \\
(-0.34 \text { to } 0.37)\end{array}$ & $\begin{array}{l}0.18 \\
(0.52 \text { to } 0.15)\end{array}$ & $\begin{array}{l}-0.49 \\
(-0.77 \text { to }-0.23)^{*}\end{array}$ \\
\hline \multicolumn{4}{|l|}{ Daytime asthma score } \\
\hline Mean baseline value & 0.79 & 0.81 & 0.87 \\
\hline $\begin{array}{l}\text { Mean ( } 95 \% \mathrm{CI}) \text { change } \\
\text { from baseline }\end{array}$ & $\begin{array}{l}-0.06 \\
(-0.24 \text { to } 0.12)\end{array}$ & $\begin{array}{l}-0.12 \\
(-0.28 \text { to } 0.04)\end{array}$ & $\begin{array}{l}-0.20 \\
(-0.35 \text { to }-0.05)\end{array}$ \\
\hline \multicolumn{4}{|l|}{ Night-time asthma score } \\
\hline Mean baseline value & 0.64 & 0.81 & 1.05 \\
\hline $\begin{array}{l}\text { Mean ( } 95 \% \text { CI) change } \\
\text { from baseline }\end{array}$ & $\begin{array}{l}0.05 \\
(-0.15 \text { to } 0.24)\end{array}$ & $\begin{array}{l}-0.06 \\
(-0.26 \text { to } 0.14)\end{array}$ & $\begin{array}{l}-0.29 \\
(-0.46 \text { to }-0.13) \dagger\end{array}$ \\
\hline \multicolumn{4}{|l|}{$\begin{array}{l}\text { Salbutamol use (mean no. of } \\
\text { inhalations/day) }\end{array}$} \\
\hline Mean baseline value & 4.02 & 4.20 & 4.28 \\
\hline $\begin{array}{l}\text { Mean ( } 95 \% \mathrm{CI}) \text { change } \\
\text { from baseline }\end{array}$ & $\begin{array}{l}0.15 \\
(-0.21 \text { to } 0.52)\end{array}$ & $\begin{array}{l}-0.18 \\
(-1.09 \text { to } 0.73)\end{array}$ & $\begin{array}{l}-0.43 \\
(-1.06 \text { to } 0.21)\end{array}$ \\
\hline
\end{tabular}

$* \mathrm{p}<0.05$ compared with placebo; $\dagger \mathrm{p}<0.001$ compared with placebo.

End point $=$ last available post-baseline measurement

Table 3 Most common adverse experiences by body system (preferred term) during the double blind treatment phase

\begin{tabular}{|c|c|c|c|}
\hline Adverse experience* & $\begin{array}{l}\text { Placebo group } \\
(n=44)\end{array}$ & $\begin{array}{l}\text { Pranlukast } \\
225 \text { mg group } \\
(n=46)\end{array}$ & $\begin{array}{l}\text { Pranlukast } \\
337.5 \mathrm{mg} \text { group } \\
(n=45)\end{array}$ \\
\hline \multicolumn{4}{|l|}{ Respiratory system } \\
\hline Asthma & 4 & 4 & 4 \\
\hline Respiratory disorder & 1 & 3 & 0 \\
\hline Dyspnoea & 0 & 2 & 2 \\
\hline Pharyngitis & 0 & 1 & 2 \\
\hline Coughing & 1 & 0 & 2 \\
\hline Bronchitis & 2 & 1 & 0 \\
\hline \multicolumn{4}{|l|}{ Gastrointestinal system } \\
\hline Abdominal pain & 0 & 2 & 2 \\
\hline Diarrhoea & 1 & 1 & 1 \\
\hline \multicolumn{4}{|l|}{ Central nervous system } \\
\hline Headache & 2 & 1 & 1 \\
\hline \multicolumn{4}{|l|}{ Resistance mechanism } \\
\hline Viral infection & 2 & 0 & 1 \\
\hline \multicolumn{4}{|l|}{ Skin } \\
\hline Pruritus & 1 & 1 & 1 \\
\hline
\end{tabular}

* Adverse experiences occurring in $>2 \%$ of total patients.

SYMPTOM SCORES

Summary symptom scores and night-time asthma scores were improved in the pranlukast treatment groups; statistical significance was observed between the pranlukast $337.5 \mathrm{mg}$ and placebo groups in summary symptoms at weeks $1(\mathrm{p}=0.033 ; 95 \% \mathrm{CI}-0.73$ to 0.03$)$ and 2 $(\mathrm{p}=0.048 ; 95 \% \mathrm{CI}-0.88$ to 0.0$)$ and at end point $(p=0.042 ; 95 \%$ CI -0.93 to -0.02$)$ and for night-time asthma scores at weeks 1 , 2 , and 4 ( $\mathrm{p}<0.05 ; 95 \%$ CI -0.58 to -0.01$)$ and at end point $(\mathrm{p}=0.016 ; 95 \% \mathrm{CI}-0.6$ to -0.06) (table 2). No significant changes in daytime symptom scores or use of $\beta_{2}$ agonists were seen.

SAFETY

Pranlukast was well tolerated during the four weeks of double blind treatment with study medication. There were no clinically significant differences between the pranlukast and placebo groups in the number of patients reporting specific adverse experiences. The most common adverse experiences, regardless of investigator's assessment of causality, are presented in table 3. There were no serious or unexpected adverse experiences attributed to the study medication, and no clinically significant changes attributed to pranlukast were noted in vital signs, electrocardiographic data, laboratory variables (clinical chemistry, haematology, and urinalysis), or physical examinations.

\section{Discussion}

Pranlukast is an orally active selective leukotriene receptor antagonist. In preclinical studies it demonstrated direct action against $\mathrm{LTD}_{4}$ by significantly inhibiting $\mathrm{LTD}_{4}$ induced airway microvascular leakage and $\mathrm{LTD}_{4}$ induced increases in cutaneous vascular permeability ${ }^{11}$ and airway eosinophils. ${ }^{12}$ Moreover, the compound was found to antagonise both exogenous and endogenous peptide leukotrienes. ${ }^{11}$ The clinical development of pranlukast in Japan was completed recently, making it the first leukotriene receptor antagonist available for the treatment of asthma, and the drug is presently on the market in Japan. Short term clinical studies have shown that pranlukast is well tolerated and is effective in reducing bronchial hyperresponsiveness ${ }^{1314}$ and allergen induced bronchoconstriction. ${ }^{10}$ After five days of dosing pranlukast has been shown to cause a greater than 25-fold shift to the right in the doseresponse curve to inhaled $\mathrm{LTD}_{4} \cdot{ }^{15}$

This multicentre study is the first conducted in Europe to evaluate the safety and tolerability of pranlukast in patients with asthma, as well as to obtain early efficacy data. The study was designed primarily as a safety and tolerability study and was not powered to determine efficacy. Nevertheless, several measures of efficacy were statistically significant for patients treated with pranlukast compared with those receiving placebo. In particular, home PEFR was significantly improved with both doses of pranlukast, although no differences between doses were observed. The improvements are modest but the patients had fairly well controlled asthma.

Both doses of pranlukast were well tolerated. No clinically significant differences were noted between the pranlukast and placebo groups in the number of patients reporting specific adverse experiences or in the total number 
of patients reporting adverse experiences or having laboratory abnormalities. The overall safety profile of pranlukast was qualitatively and quantitatively indistinguishable from placebo.

This study demonstrates that pranlukast is well tolerated and has clinical activity in patients who have asthma. The data are consistent with clinical trials conducted in Japan and lend further support to the accumulating evidence that leukotriene receptor antagonists have beneficial effects in patients with chronic asthma.

The investigators participating in the International Study Group AJ Winning, E Ramhamadany, MD Blagden, BS Young, J Repper; France: J-C Pujet, C Dubruoil, F Macone, B Aguilaniu, H Kafe, JP Moreau, JM Liegaux, L Bernabeu, A-B Tonnel, Maesen. The study was funded by SmithKline Beecham.

1 Murphy RC, Hammarstrom S, Samuelsson B. Leukotriene C: a slow-reacting substance from murine mastocytoma cells. Proc Nat Acad Sci USA 1979;76:4275-9.

2 Taylor IK, O'Shaughnessy KM, Fuller RW, Dollery CT. Effect of cysteinyl-leukotriene receptor antagonist ICI 204, 219 on allergen-induced bronchoconstriction and airway hyperactivity in atopic subjects. Lancet 1991;337:690-4.

3 Rasmussen JB, Margolskee DJ, Eriksson L-O, Williams VC, Anderson KE. Leukotriene (LT) $\mathrm{D}_{4}$ is involved in antigeninduced asthma: a study with $\mathrm{LTD}_{4}$ receptor antagonist, MK-571. Ann NY Acad Sci 1991;629:436.

4 Manning PJ, Watson RM, Margolskee DK, Williams VC, Schwartz JI, O'Byrne PM. Inhibition of exercise-induced bronchoconstriction by MK-571, a potent leukotriene $\mathrm{D}_{4}$ bronchoconstriction by MK-571, a potent leukotriene
receptor antagonist. $N$ Engl $\mathcal{F}$ Med 1990;323:1736-9.

5 Israel E, Dermarkian R, Rosenberg M, Sperling R, Taylor $\mathrm{G}$, Rubin P, et al. The effects of a 5-lipoxygenase inhibitor on asthma induced by cold, dry air. N Engl f Med 1990; 323: $1740-4$.

6 Cloud ML, Enas GC, Kemp J, Platts-Mills T, Altman LC Townley R, et al. A specific $\mathrm{LTD}_{4} / \mathrm{LTE}_{4}$ receptor antagonis improves pulmonary function in patients with mild chronic asthma. Am Rev Respir Dis 1989;140:1336-9.

7 Israel E, Rubin P, Kemp JP, Grossman J, Pierson W, Siegel $\mathrm{SC}$, et al. The effect of inhibition of 5-lipoxygenase by zileuton in mild to moderate asthma. Ann Intern Med 1993;119:1059-66.

8 Spector SL, Smith LJ, Glass M, and the Accolate Asthma Trials Group. Effects of 6 weeks of therapy with oral doses of ICI 204,219, a leukotriene $\mathrm{D}_{4}$ receptor antagonist, in subjects with bronchial asthma. Am f Respir Crit Care Med 1994;150:618-23.

9 Yamaguchi T, Kohrogi H, Honda I, Kawano O, Sugimoto $\mathrm{M}$, Ando $\mathrm{M}$, et al. A novel leukotriene antagonist, ONO1078 , inhibits and reverses human bronchial contraction induced by leukotrienes $\mathrm{C}_{4}$ and $\mathrm{D}_{4}$ and antigen in vitro. Am Rev Respir Dis 1992;146:923-9.

10 Taniguchi Y, Tamura G, Honma M, Aizawa T, Maruyama $\mathrm{N}$, Shirato $\mathrm{K}$, et al. The effect of an oral leukotriene antagonist, ONO-1078, on allergen-induced immediate bronchoconstriction in asthmatic subjects. 7 Allergy Clin Immunol 1993;92:507-12.

11 Nakagawa N, Obata T, Kobayashi T, Okada Y, Nambu F, Terawaki $\mathrm{T}$, et al. In vivo pharmacologic profile of ONO1078. a potent, selective and orally active peptide leukotriene (LT) antenist. Fapan 7 Pharmacol 1992;60:217

12 Underwood DC, Osborn RR, Bochnowicz S, Newsholme SJ, Torphy TJ, Hay DWP. Pranlukast, a potent and selective cysteinyl-leukotriene (CysLT) receptor antagonist, attenuates pro-inflammatory responses induced by leukotriene (LT) $\mathrm{D}_{4}$. Eur Respir f 1995;8(Suppl 19):288s.

13 Fujimura M, Sakamoto S, Kamio Y, Matsuda T. Effect of a leukotriene antagonist, ONO-1078, on bronchial hyperresponsiveness in patients with asthma. Respir Med 1993;87:133-8.

14 Taki P, Suzuki R, Tori K, Mutsamoto S, Taniguchi $\mathrm{H}$, Tukagi K. Reduction of the severity of bronchial hyperresponsiveness by the novel leukotriene antagonist 4-oxo8-[4-(4-phenyl-butoxy)benzoylamino]-2-(tetrazol-5-yl)4H-1-benzopyran hemihydrate. Drug Res 1994;44:330-3.

15 O'Shaughnessy TC, Georgiou P, Howland K, Dennis M, Compton CH, Barnes N. The effect of pranlukast, an oral leukotriene antagonist, on leukotriene $\mathrm{D}_{4}\left(\mathrm{LTD}_{4}\right)$ oral leukotriene antagonist, on leukotriene $\mathrm{D}_{4}\left(\mathrm{LTD}_{4}\right)$
challenge in normal volunteers. Thorax $1997 ; 52: 524-7$. 